\title{
Hearing Impairment Disability Salience in Students: Measures and Correlates with Social Acceptance in Regular Schools
}

\author{
*Wadesango N, \\ nwadesango@ufh.ac.za \\ **Gudyanga E, \\ ***Eliphanos Hove \\ **Gudyanga A \\ ${ }^{*}$ University of Fort Hare, TLC, East London, RSA \\ ${ }^{* *}$ Midlands State University, Faculty of Education, Gweru, Zimbabwe \\ ***Zimbabwe Open University, Mat South, Zimbabwe
}

\section{Doi:10.5901/mjss.2014.v5n9p415}

\section{Abstract}

This study sought to investigate challenges faced hearing impaired students in Bulawayo urban regular secondary schools. The descriptive survey was adopted in this study. The sample consisted of twenty-five (25) specialist teachers, eighty (80) regular teachers, five (5) school administrators and fifty-six (56) students with hearing impairment who were randomly selected. Data were collected through structured questionnaires, observations and face to face interviews. The study showed that Bulawayo Urban regular secondary schools were not ready to include students with hearing impairment. It can be concluded that learners with hearing impairment in inclusive secondary school settings experienced emotional and behaviour challenges because they were less accepted by regular teachers than hearing students in the regular classrooms and their behaviour was interpreted as negative. Recommendations made were that the training for teachers to teach effectively in diverse classrooms needs to be taken as a priority. Special Education should not be offered just as a mere component to trainee secondary school teachers.

Keywords: Hearing impairment, disability, students, regular schools, social acceptance

\section{Background}

Every child has unique characteristics, interests, abilities, and learning needs, therefore education systems should be designed and education programmes implemented, to take into account the wide diversity of these characteristics and needs, (Adoyo, 2008). The inclusion of students with hearing impairment in regular schools is pivotal to their educational success. Inclusion refers to the situation in which the students with disabilities, for example children with hearing impairment are educated in mainstream classes and provided with the necessary Special Education support services and the needed supplementary aids in age appropriate classes, (Hardman, Drew and Egan, 2005).It fosters an attitude of unqualified acceptance and the need to support the growth of the student with hearing impairment at all levels. The practice of inclusion emerged as a counter reaction to problems encountered during integrative educational provision.

In Zimbabwe, significant efforts have been made to cater for the education of children with hearing impairment through special schools, integration units and the training of specialist teachers for the hearing impaired students, (Mushoriwa and Gasva, 2008). Inclusive education option is expected for all primary schools in Zimbabwe but there is no specific policy on the provision of inclusive education to students with hearing impairment in Secondary schools. Students with mild to moderate hearing impairment tend to receive instruction in classrooms for hearing students, with resource room support. A specialist teacher for the hearing impaired students is supposed to take charge of the resource room at every school where these students are included. These teachers offer clinical instruction. The efforts of the teacher of the deaf are augmented by the services of a peripatetic remedial tutor from the Schools Psychological Services and Special Education Department, who assist the teachers with instructional design, delivery and evaluation. The peripatetic remedial tutor also assists with assessment and placement of hearing impaired students. Although these students are accessing education, indicators are that not much of normalization is taking place. In a study of inclusive education 
programmes in Kenya, Morta (1994) found out that inclusion programmes were viewed by schools as not for every child with disabilities. They indicated that the schools were facing some challenges.

During teaching practice supervision, the researcher noted that the inclusion of students with hearing impairment was not meeting the expected standards. Al-Zyoudi (2006) assert that the main problem facing special education for hearing impaired students was the paradox of normalisation that is how to provide needed special education so normally that it would not create detrimental side effects. Booth and Ainscow (2003) in his review of Special Education developments since the 1990 world conference, also noted that learners facing barriers continue to be the most excluded from education. There is a risk of students with hearing impairment being excluded from the teaching and learning that goes on, unless measures are taken to make sure they are fully included. This prompted this study on problems associated with the inclusion of hearing impaired students in secondary schools in Bulawayo Urban.

\section{Research Methodology}

The descriptive survey was chosen for its strengths, one which is its breadth of coverage (Johnson, 1994). The major purpose of surveys is to describe the characteristics of a population, to find out how the members of a population distribute themselves on one or more variables, (Cohen and Manion, 1994). Information is collected from a group of people in order to describe some aspects or characteristics (such as abilities, attitudes and challenges / problems) of the population of which that group is part. Data were collected through structured questionnaires, observation and face to face interviews. In this study based on challenges faced by students with hearing impaired students in Bulawayo urban regular secondary schools, twenty-five (25) specialist teachers, eighty (80) regular teachers, five (5) school administrators and fifty-six (56) students with hearing impairment made up the population. This was in line with Leedy's (1997) suggestion that the population for a study must be carefully chosen and defined. It must be specifically delineated in order to set precise parameters for insuring discreetness of the population. Simple random sampling was used for selecting the participants of the study. This is a procedure that gives each of the total sampling units of the population an equal and known none zero probability of being selected, (Frankfort -Nachmias and Nachmias, 1996). In order to use a table of random numbers for the purpose of selecting participants, the researcher had to first number all the elements in the sampling frame. Tables of random numbers were composed, they ranged from one to as high a number as the total size of the sampling frame.

\section{Data Presentation and Analysis}

\subsection{Research question 1:}

What are the characteristics of students with hearing impairment in regular secondary schools?

The research question sought to find out if teachers in inclusive secondary schools were aware of the characteristics of students with hearing impairment in their classrooms. Item four, (4) in both the questionnaire for specialist teachers and regular teachers addressed the research question.

Table 1: Views held by specialist teachers on characteristics of children with hearing impairment.

$\mathrm{N}=12$

\begin{tabular}{|c|c|c|c|c|c|c|}
\hline Questionnaire item & \multicolumn{2}{|c|}{ Always } & \multicolumn{2}{|c|}{ Sometimes } & \multicolumn{2}{|c|}{ Never } \\
\hline & f & $\%$ & $F$ & $\%$ & f & $\%$ \\
\hline Children with hearing impairment may be unaware of conversational cues. & 12 & 100 & - & - & - & - \\
\hline They show immature behavior & 8 & 67 & 1 & 8 & 3 & 25 \\
\hline They may appear absent minded & 7 & 58 & 1 & 8 & 4 & 33 \\
\hline Socialisation with peers with normal hearing is constrained & 8 & 67 & 1 & 8 & 3 & 25 \\
\hline They show a emotional and behaviour problems & 11 & 92 & - & - & 1 & 8 \\
\hline They manifest feelings of inadequacy & 12 & 100 & - & - & - & - \\
\hline They experience difficulties in relating with others & 9 & 75 & - & - & 3 & 25 \\
\hline Inclusion for hearing impaired students is stressful & 6 & 50 & - & - & 6 & 50 \\
\hline
\end{tabular}

All the respondents (100\%) expressed that students with hearing impairment on many occasions are unaware of conversational cues. The indications were that students with hearing impairment miss out on important communication 
cues. Sixty-seven percent (67\%) of the respondents acknowledged that students with hearing impairment exhibited immature behaviour whilst twenty-five percent (25\%) thought to the contrary. The least number of respondents (8\%) indicated that children with hearing impairment sometimes show immature behaviour. Fifty-eight percent (58\%) of the specialist teachers confirmed that students with hearing impairment always appear absent minded or not paying attention. Thirty-three percent said they never appear absent minded whilst eight percent (8\%) thought they sometimes appear absent minded or not paying attention. Sixty-seven percent (67\%) of the respondents confirmed that socialisation between students with hearing impairment and peers with normal hearing are constrained. Twenty-five percent (25\%) of the specialist teachers indicated that students with hearing impairment never found socialisation with the hearing students constrained. On the other hand, only eight percent $(8 \%)$ of the specialist teachers indicated that socialisation is constrained. Table 2 presents regular teachers' responses to statements on awareness of the characteristics of hearing impaired students in the regular classroom.

Table 2: Regular teachers' views on characteristics of children with hearing impairment. $\mathrm{N}=12$

\begin{tabular}{|c|c|c|c|c|c|c|}
\hline Questionnaire item & \multicolumn{2}{|c|}{ Always } & \multicolumn{2}{|c|}{ Sometimes } & \multicolumn{2}{|c|}{ Never } \\
\hline & f & $\%$ & f & $\%$ & f & $\%$ \\
\hline Children with hearing impairment may be unaware of conversational cues. & 5 & 21 & 16 & 67 & 3 & 13 \\
\hline They display immature behavior & 2 & 8 & 15 & 63 & 7 & 29 \\
\hline They may appear absent minded or not paying attention & 2 & 8 & 16 & 67 & 6 & 25 \\
\hline Socialisation with peers with normal hearing is constrained & 2 & 8 & 18 & 75 & 4 & 17 \\
\hline They show a high incidence of emotional and behaviour problems & 2 & 8 & 14 & 58 & 8 & 33 \\
\hline They manifest feelings of inadequacy & 3 & 13 & 17 & 80 & 4 & 17 \\
\hline
\end{tabular}

Regular teachers indicated that hearing impaired students were sometimes unaware of conversational cues. This is shown by sixty -seven (67\%) of the respondents who confirmed that it happened sometimes. However, twenty-one percent (21\%) thought they manifested the behaviour always and thirteen percent (13\%) indicated that they never manifested the behaviour. It was also shown that hearing impaired students sometimes displayed immature behaviour. Table 9 shows that sixty-six (66\%) of the respondents thought they manifested immature behaviour. Twenty-nine percent $(29 \%)$ of the respondents dismissed the notion that the hearing impaired students display immature behaviour. Sixty seven percent (67\%) of the respondents confirmed that students with hearing impairment sometimes appeared absent minded. Eight percent (8\%) of the respondents thought they appeared absent minded always; while twenty-five percent (25\%) thought they did not display the trait. Regular teacher respondents commented that hearing impaired students' characteristics were lacking in many respects. They were agreed that the behaviour of hearing impaired students contributed to the regular teachers' and hearing peers' negative attitudes towards them. Their behaviour was said to be unpredictable and this was depended on the attitudes of teachers and peers. They behaved in socially appropriate ways if they were accepted and exhibited maladaptive behaviour if they were rejected.

In the observations the researcher noted that the interaction between students with hearing impairment and their hearing counterparts was not smooth going. Grouping according to whether hearing or not was quite visible. Students with hearing impairment were generally isolated. Surprisingly they signed to each other very well. Students with hearing impairment were not as free as their hearing counterparts. They manifested low self esteem. However there were very few incidences when they displayed immature behaviour. Students with hearing impairment looked apprehensive in the classrooms as the regular teachers went round the class marking the students' work. Communication problems were prevalent and at one time the researcher saw chaos. When the hearing impaired students went for clinical remediation in the resource rooms, they were in high spirits and they worked very well with the specialist teacher.

\subsection{Research question 2:}

Is the teaching and learning environment adapted to suit the needs of hearing impaired students in secondary school inclusive setting?

The research question intended to explore the barriers to teaching and learning of hearing impaired students in inclusive secondary school settings. It sought to find out if the teaching and learning environment was adapted to suit the needs of hearing impaired students and to reveal ways in which the regular school environment was a challenge to students with hearing impairment. Questionnaire items 5-7 in the questionnaire for regular teachers and items 5-11 in the questionnaire for specialist teachers attempted to answer this research question 
Table 3: Regular teachers' responses on communication adaptations in classrooms used by students with hearing impairment. $\mathrm{N}=24$

\begin{tabular}{|l|c|c|c|c|}
\hline Questionnaire item & \multicolumn{2}{|c|}{ Available } & \multicolumn{2}{c|}{ Not available } \\
\hline & f & $\%$ & f & $\%$ \\
\hline Provision for sign language & 12 & 50 & 12 & 50 \\
\hline Oral interpretation services & 14 & 58 & 10 & 42 \\
\hline Provision of student lecture notes & 13 & 54 & 11 & 46 \\
\hline Inclusion of sign language in teaching & 11 & 46 & 13 & 54 \\
\hline Provision of written or captioned school announcements & 20 & 8 & 4 & 16 \\
\hline
\end{tabular}

Communication adaptations in place in inclusive secondary schools for students with hearing impairment included providing oral interpretation services indicated by fifty-four percent (54\%) and provision of written or captioned school announcements indicated by eighty-three percent (83\%). Opinion on sign language provision was divided at fifty percent (50\%), hence it was not clear what transpired on it. What was clear and loud was that secondary schools did not offer sign language training in their sessions. The regular teachers cited communication problems as rife in classrooms where hearing impaired students were included. They noted that these students experienced difficulties accessing information that was presented verbally as evidenced by their failure to take instructions and their poor performance academically. Table 4 presents responses from specialist teachers on the nature of the teaching and learning environment in regular secondary schools for use by students with hearing impairment.

Table 4: Do you assist in the teaching of hearing impaired students in your school? $\mathrm{N}=12$

\begin{tabular}{|c|c|c|}
\hline Response & f & $\%$ \\
\hline Yes & 6 & 50 \\
\hline No & 6 & 50 \\
\hline Total & 12 & 100 \\
\hline
\end{tabular}

Table 4 indicates a 50-50 situation, where fifty-percent (50\%) of the respondents indicated that they assisted in the teaching of students with hearing impairment and another fifty percent (50\%) said they did not. All specialist teachers who indicated that they were consulted confirmed that they did sign language interpretation and a bit of speech training and auditory training. At least hearing impaired students received important requirements for successful inclusion in the form of individual instruction, special therapy opportunities and cooperation with specialist teachers. Where these services were nonexistent the hearing impaired students faced a host of challenges that impeded their teaching and learning in regular secondary schools. This is in line with Booth and Ainscow (2003) who proposed that schools should offer speech therapy, auditory training and IEP services. In the case of regular teachers, lack of expertise to teach hearing impaired students made them to feel shortchanged, as a result of having a hearing impaired student in the classroom. This was a challenge to the regular teachers. Teaching and learning of students with hearing impairment was heavily affected.

On communication problems encountered by students with hearing impairment in inclusive secondary schools, the specialist teachers noted the following: engaging in group discussions with hearing peers, use of speech by class teachers in most cases, and poor concept development especially in language intensive subjects (e.g. History, English and Commerce). This was a challenge to students with hearing impairment because communication problems impede their teaching and learning in secondary schools. These findings are contrary to those by Stinson and Whitmire (2000) who found out that in Kenya the deaf and hard of hearing had access to teacher communication and that discussions and other activities were structured in a manner that allowed the students to participate gainfully. Item five (5) in the questionnaire for regular teachers intended to find out the state of adaptations in regular secondary schools. Table 5 presents regular teachers' responses to physical adaptations in secondary schools where students with hearing impairment are included.

Table 5: Regular teachers' responses on physical adaptations in secondary schools where students with hearing impairment are included.

\begin{tabular}{|l|c|c|c|c|}
\hline Adaptation & \multicolumn{2}{|c|}{ Available } & \multicolumn{2}{c|}{ Not available } \\
\hline & F & $\%$ & F & $\%$ \\
\hline Acoustically treated rooms & 2 & 8 & 22 & 92 \\
\hline Carpeted floors & 2 & 8 & 22 & 92 \\
\hline Good lighting system & 10 & 42 & 14 & 58 \\
\hline
\end{tabular}


Information in Table 5 shows that there were no physical adaptations in inclusive secondary school classrooms for students with hearing impairment. This is shown by ninety-two percent (92\%) who indicated that there were no acoustically treated rooms, another ninety-two percent (92\%) who said there were no carpeted floors and fifty-eight percent $(58 \%)$ who confirmed there was no good lighting system. The evidence was overwhelming. Therefore the indications are that hearing impaired students faced serious challenges in regular secondary schools. The findings fall short of Andrews and Lupart's (2000) projected least restrictive environment for students with hearing impairment. The researchers observed that high working noise can cause problems for pupils who rely on hearing aids because all sounds are picked up and amplified by an aid and it is very difficult to discern and sift out those sounds upon which the child should act from all those reaching his or her ears.

During observations of the teaching and learning environment in schools studied, the researcher noted that the learning and teaching environment was unsuited to the challenges that the hearing impaired students faced in the regular secondary school classrooms. In all the four schools visited the physical structures were not suitable in acoustical terms. Even though the researcher did not encounter students wearing hearing aids, the noise levels were at times too high. In one school the hearing aids were heaped in a corner and indications were that they were not used. When the researcher asked the regular teachers if they knew the function and operation of hearing aids, they indicated ignorance about them. Most of the students with hearing impairment interviewed indicated dissatisfaction with the teaching and learning environment and nonuse of hearing aids. They indicated that they did not want much support but an environment that is least restrictive. However, they generally felt that the regular school was the right place for them.

From the observations made, the bulk of the regular teachers who taught different subjects did not use sign language as they taught. The hearing impaired students were therefore struggling to make sense of the English language that dominated classroom communication. It appeared that Signed English conflicted with the syntactic features of a visual /manual language, creating confusion. Many misunderstandings arose due to wrong words or sentences being misinterpreted. Stress and frustrations on account of communication difficulties encountered by students were quite conspicuous. The research findings confirm Booth and Ainscow's (2003) concern that lack of key teaching adaptations for students with hearing impairment is a disaster in their education.

\subsection{Research question 3:}

What is the attitude of regular teachers towards hearing impaired students in inclusive secondary schools?

The research question intended to explore the attitude of regular teachers towards hearing impaired students in regular secondary schools. Questionnaire item 9 in the questionnaire directed to regular teachers; item 12 in the questionnaire directed to specialist teachers and item 5-6 in the interview guide for students with hearing impairment, addressed the inquiry into attitudes of regular teachers towards students with hearing impairment in inclusive settings.

Table 6: Regular teachers' responses on teachers' attitudes.

\begin{tabular}{|l|c|c|c|c|c|c|}
\hline Questionnaire item & \multicolumn{2}{|c|}{ Always } & \multicolumn{2}{|c|}{ Sometimes } & \multicolumn{2}{c|}{ Never } \\
\hline & $\mathrm{f}$ & $\%$ & $\mathrm{~F}$ & $\%$ & $\mathrm{f}$ & $\%$ \\
\hline I view hearing impaired students just like other hearing students & 10 & 42 & 14 & 58 & - & - \\
\hline I like assisting hearing impaired students with their academic work & 14 & 58 & 8 & 33 & 2 & 8 \\
\hline Including hearing impaired students in regular classes makes them well adjusted & 8 & 33 & 15 & 65 & 1 & 4 \\
\hline I think the inclusion of children with hearing impairment is a noble idea & 14 & 58 & 5 & 21 & 5 & 21 \\
\hline
\end{tabular}

Information on Table 6 shows that the attitudes of regular teachers towards the inclusion of children with hearing impairment were positive. This is shown by fifty-eight percent (58\%) of the respondents who (sometimes) viewed hearing impaired students the same as their hearing counterparts, Also forty-two percent (42\%) always viewed them as having positive attitude towards the inclusion of students with hearing impairment. In total one hundred percent (100\%) of the respondents confirmed that regular teacher attitudes towards students with hearing impairment were positive. It is worth noting that teacher acceptance or resistance to the inclusion of students with hearing impairment into regular education classrooms is related to the knowledge base and experiences of teachers (Sack, 1988). Fifty-eight percent (58\%) of the respondents indicated that they were always willing to assist hearing impaired students with their academic work. Thirtythree percent (33\%) of the respondents indicated they sometimes helped them, while eight percent (8\%) confirmed that they never assisted them. Sixty-five percent (65\%) of the respondents believed that inclusion of children with hearing impairment would make students with hearing impairment well adjusted. This is an indicator of positive attitudes. In line with this, thirty-three percent (33\%) of the respondents reported great behaviour improvement as a result of inclusion. 
Regular teacher respondents supported the inclusion of children with hearing impairment in regular school classrooms. This was indicated by seventy-nine percent $(79 \%)$ of the respondents who thought that the inclusion of children with hearing impairment in regular secondary schools was a noble idea. However, twenty-one percent (21\%) were against the idea. Item 9 in the questionnaire for specialist teachers sought to find out attitude of regular teachers towards students with hearing impairment in mainstream classrooms. One hundred percent $(100 \%)$ of the specialist teacher respondents thought that regular teachers' attitudes were negative. Most of the hearing impaired students expressed their feelings of being outsiders in a variety of contexts. They indicated that the regular teachers did not understand them in the manner they understood their counterparts with normal hearing. They could not rule out likelihood of regular teachers harbouring negative attitudes. They indicated that their interaction with the regular teachers and students with normal hearing was affected by negative attitudes. The findings are in line with Chimedza and Peterson's (2001) study of deaf students and their experiences in the mainstreamed Turkish High Schools.

\subsection{Research Question 4:}

Are teachers conversant with practices facilitating the inclusion of hearing impaired students in secondary schools?

The research question intended to find out whether regular teachers were conversant with practices facilitating the inclusion of hearing impaired students. Questionnaire items 11 in the questionnaire for specialist teachers and questionnaire item 10-11 in the questionnaire for regular teachers addressed this research question. Responses gathered during the research are presented below. On teacher pupil ratio in secondary schools, a ratio of 1:30 (one teacher to thirty students) was felt too large for the teacher to have spare time to attend to students with hearing impairment who may need extra help. One respondent commented, "It is better they remain in special schools or resource units until the teacher pupil ratio is reduced to 1:20". By implication placement of hearing impaired students in large classes exposed them to the challenge of physically being included but academically excluded. According to Adoyo,(2008) inclusion may not work unless the regular classroom changes to accommodate all learners and in the process desirable services be offered to all students with or without disabilities.

According to research findings, the present crop of regular teachers does not possess the knowledge and skills to manage children with hearing impairment in regular secondary schools. One suggestion was that regular teachers should be trained in sign language.

Specialist teachers indicated that inclusion of students with hearing impairment goes with provision of support services. They felt that inclusion without support is a barrier to learning and teaching of students with hearing impairment in a regular secondary school classroom. One respondent described it as "student dumping". Also in the majority of cases, the respondents mentioned the need for a specific policy on the education of students with hearing impairment in regular secondary schools. Specialist teachers further indicated that regular teachers did not value and benefit from collaboration with specialist teachers. They indicated that this was important for sharing information. Curriculum was one of the obstacles that needed to be carefully designed and adapted to suit the learning needs of hearing impaired students. Specialist teachers identified a number of things that needed to be added to the teaching and learning of students with hearing impairment. These were allocating additional time to students with hearing impairment, modified grading of students' work, individual educational plans, individual instruction and modifying physical structures and tasks. The addition of vocational subjects, (sign language training, auditory training and speech training) was also suggested by specialist teachers of students with hearing impairment.

Research conducted through interviews carried out with hearing impaired students covered a wide range of aspects to do with challenges faced in the inclusion of students with hearing impairment in secondary schools and measures that can be put in place to improve the conditions in these schools. Some of the student respondents said that they were taught by regular teachers in mainstream classes and sometimes received clinical remediation from resource rooms manned by specialist teachers in the schools. They indicated absence of instruction tailored to their individual learning needs.

\section{Discussion}

A number of important observations were made in this study. The general picture that emerged from the study is that the potential for inclusion was great but this potential could not be realized because of factors intrinsic in the learners with hearing impairment and extrinsic to the learner and arise from the education system.

Research findings on the characteristics of students with hearing impairment in inclusive secondary schools show that when the student's characteristics are described by regular teachers they are far more frequently described in 
negative terms than when they describe students with normal hearing. This is not the case with specialist teachers of students with hearing impairment. Findings from regular teachers were that, hearing impaired students experienced problems when relating to hearing students, appeared absent minded, experienced constrained socialisation and showed a high incidence of emotional behaviour problems. However, specialist teachers of students with hearing impairment had views that differed from those of the regular teachers on some dimensions of their characteristics. They did not support the view that hearing impaired students displayed immature behaviours and showed a high incidence of emotional and behaviour problems. This shows that specialist teachers of students with hearing impairment were more positive towards them than the regular teachers in inclusive settings. However, both regular teachers and specialist teachers of students with hearing impairment concurred that students with hearing impairment in inclusive settings were isolated and had low self esteem. It was revealed that because of isolation and prejudice their behaviour at times became irrational. Also what seems to emerge from the study is that regular teachers in inclusive secondary schools did not quite understand the students with hearing impairment but what is clear from the observations made is that their behaviour depended on the attitudes of their teachers and peers. According to Reedy (1994) students with hearing impairment behaved in socially appropriate ways if they were accepted and exhibited maladaptive behaviour if they were rejected.

The study also established that there were communication problems within classes where hearing impaired students were included. This was because the communication adaptations that were put in place in inclusive secondary schools were seen as inadequate. The study confirmed the availability of oral interpretation services, provision of lecture notes before hand, and written or caption school announcements. However, it was highlighted that students with hearing impairment experienced difficulties accessing information that was presented verbally. In turn, students with hearing impairment confirmed that they encountered problems with subjects which were verbally oriented. In the regular classrooms, they did Mathematics, Practical Subjects and a dose of English. They did not do Science, Commerce, Geography and other language based subjects.

Students with hearing impairment indicated that they had problems with departmental teaching where they would meet different teachers for different subjects. The situation may present difficulties for the students as they would need to adjust to multiple teachers' speech and teaching styles. Perhaps the problem was worsened by the absence of subjects such as speech training, auditory training, language development programmes and sign language training which may improve access to the ordinary school curriculum. This view is in line with Chimedza and Peterson's (2003) view that although hearing impaired students may follow the same curriculum as their hearing counterparts they have extra subjects they should do in order to help them access the core curricula.

There is evidence in the study that educational adaptations for students with hearing impairment in inclusive secondary schools were not fully addressing their learning needs. Besides the curriculum being unmodified, regular teachers did not prepare individual educational programmes for students with hearing impairment. Also regular teachers lacked knowledge and skills to handle students with hearing impairment in secondary schools. The findings are in line with Chakuchichi et al. (2003) assertion that as a result of lack of adapted teaching and learning secondary education was inaccessible for students with hearing impairment.

The study further established that physical structures in secondary school classrooms used by students with hearing impairment were not adapted to suit the needs of learners with hearing impairment. Rooms were not acoustically treated and there were no carpets to cushion noise in the rooms. Audiological laboratories for hearing testing were not available in inclusive secondary schools except for one school which had one. Unfortunately the laboratory was nonfunctional. This raises doubts about the state of preparedness of regular secondary schools studied. The findings confirm Sacks' (2001) report of a study which revealed that the regular teachers were the least prepared for inclusive education of children with disabilities.

The study also found that regular teacher attitudes towards hearing impaired students in inclusive secondary schools were a contentious issue. Regular teachers admitted that they treated students with hearing impairment just like their hearing counterparts and were willing to assist them with their academic work. They were positive towards them. On the contrary specialist teachers of students with hearing impairment considered the regular teachers' attitudes to be negatively inclined. Also results from observation of the teaching and learning environment confirmed hearing impaired students' uneasiness and low preference of regular teachers and hearing peers in inclusive settings. There were high chances of regular teachers' attitudes being negative. Hegarty (1994) and Peterson (1994) assert that regular teachers have been described as becoming more frustrated, demoralised and distressed by not being able to cater for the increased diversity of needs in their regular classrooms.

On practices that influence the inclusion of students with hearing impairment in secondary schools, the research found that the high teacher- pupil ratio of one teacher to thirty students (1:30) or more had adverse effects on the inclusion drive. There was no room for attending to students with hearing impairment when a regular teacher had a big 
class load. The regular teacher did not possess the expertise to handle students with hearing impairment. The findings confirm Hegarty's (1993) study that revealed that teachers in regular secondary schools may not be familiar with the patterns of learning difficulty, essential curriculum, materials and resources needed.

The research established that to improve the expectations of teachers there was need to develop their knowledge about students with hearing impairment and their abilities. An environment of professional collaboration and a specific policy on the education of children with hearing impairment in inclusive settings was felt mandatory. The findings are in support of Corbet's (2001) who proposes important requirements for successful inclusion as individualised instruction, speech therapy, opportunities, cooperation with specialist teachers, in-service training of regular teachers, parents' involvement, guidance and support. Reid (2005) also noted that the special education teacher and the regular teacher combine their complementary professional knowledge and skills and work simultaneously in regular education classrooms.

\section{Conclusion}

The study showed that Bulawayo Urban regular secondary schools were not ready to include students with hearing impairment. Regular teachers were not aware of the characteristics of hearing impaired students to manage them properly in inclusive settings and they were not conversant with practices that facilitate their inclusion. The study established that the regular teachers were not aware of them. Specialist teachers were more accepting to learners with hearing impairment than regular teachers. It can be concluded that learners with hearing impairment in inclusive secondary school settings experienced emotional and behaviour challenges because they were less accepted by regular teachers than hearing students in the regular classrooms and their behaviour was interpreted as negative

\section{Recommendations}

Basing on the research findings, the following recommendations are made:

- Training for teachers to teach effectively in diverse classrooms needs to be taken as a priority. Special Education should not be offered just as a mere component to trainee secondary school teachers.

- Schools should pay attention to additional ways in which teachers who teach hearing impaired learners can be supported. The additional time required to prepare for diverse classes can be acknowledged through reduced teaching and extra mural loads. Time tables can be adjusted to allow for collaborative planning.

\section{References}

Adoyo, P.O. (2008). Educating Deaf Children in an Inclusive setting in Kenya: Challenges and Considerations. Nairobi: University of Kenya.

Al-Zyoudi, E. (2006). Teachers' Attitudes towards Inclusive Education in Jordanian schools, International Journal of Special Education, 21 (2):2332

Andrews, J. and Lupart, J. (2000). The inclusive classroom: Educating Exceptional Children. London: Nelson Thomson.

Booth, T. and Ainscow, M. (2003). The index for Inclusion. (2nd Edition). Bristol: Centre for studies on Linguistic Education.

Chakuchichi, D. D. Chimedza, R. M. Chiinze, M. M. and Kaputa, T. M. (2003). Including the Excluded. Issues in Disability and Inclusion. Harare: Zimbabwe Open University.

Chimedza, R. and Peters, S. (2001). Disabilities and Special Needs Education in an African Setting. Harare: College Press.

Cohen, L. and Manion, L. (1994). Research Methods in Education. London: Routledge.

Frankfort-Nachmias, C. and Nachmias, D. (1996). Research Methods in the Social Sciences. London: Arnold

Hardman, M. I. Drew, G. L. and Egan, M. W. (2005). Human Exceptionality in Society, School and Family. Boston: Allyn and Bacon.

Johnson.D. (1994). Research Methods in Educational Management. London: Longman Group UK Ltd.

Leedy, P.D. (1997). Practical Research, Planning and Design. New York: MacMillan Publishers.

Moores, D.F. and Martins, D.S. (2006). Deaf Learners: Developments in curriculum and Instruction.Washington: Gallaudet University Press.

Morta, (1994). Education of the Deaf. Australian Journal of Education of the Deaf, 2 (1):23-29

Mushoriwa, T. and Gasva, O.(2008). Attitudes of Secondary School pupil towards the inclusion of Educably Mentally Challenged pupils in Harare. The Zimbabwe Bulletin of Teacher Education.ISSN, 1022-3800 Vol 15(1):24

Peterson, J. (1994). Regular Teachers' Attitudes towards the Integration of Hearing Impaired Students. A Government High Schools Educational Research: Innovation and Practice 2: 2-14.

Reed, M. (1994). Educating Hearing Impaired Children in Ordinary and Special Schools. Milton Keyness: Open University Press.

Reid, G. (2005). Learning Styles and Inclusion. London: Paul Chapman Publishing.

Sacks, A. (2001). Special Education: Contemporary Education Issues. Oxford: ABC-Clio,Inc.

Stinson, M.S. and Whitmire, K.A. (2000). "Adolescents who are deaf or hard of Hearing: A Communication Perspective on Educational Placement": Topics in Language Disorder, 20 (2): 58-73. 